\title{
Заключение
}

Был разработан и реализован на языке программирования С\# алгоритм распознавания эмоций. Алгоритм был протестирован на модифицированном наборе данных The Cohn-Kanade Dataset, показал сравнительно хороший результат. Точность на тренировочных данных составила 94\%. Точность на данных, не входивших в обучение нейронной сети, составила $61 \%$.

Данный результат можно считать успешным для созданного прототипа, так как набор данных, на котором обучалась нейронная сеть, достаточно мал для задачи распознавания эмоций (набор содержит чуть меньше тысячи изображений).

В дальнейшем планируется, улучшить работу алгоритма за счет увеличения объёма тренировочного набора данных, взяв за основу базу данных AffectNet, содержащую примерно 440.000 элементов, размеченных вручную.

Также планируется протестировать различные конфигурации модуля построения активной модель внешнего вида, для оптимизации алгоритма.

$$
* * *
$$

1. Сорокин А.Б. Сверточные нейронные сети: примеры реализаций: Учебно-методическое пособие по выполнению практических работ для студентов, обучающихся по направлению 09.03.04 «Программная инженерия» по профилю «Системы поддержки принятия решений». / под редакцией Коваленко С.М. - М., Российский технологический университет, 2020.

2. Сорокин А.Б. Искусственные нейронные сети прямого распространения: учебно-методическое пособие / Сорокин А.Б., О.В. Платонова. - М.: МИРЭА - Московский технологический университет, 2018.

3. База данных FER-2013. URL: https://www.kaggle.com/msambare/fer2013

4. Документация по библиотеке для языка C\# EmguCV (OpenCV). URL: http://www.emgu.com/wiki/index.php/Documentation

5. Документация по библиотеке для языка C\# Keras.NET. URL: https://github.com/SciSharp/Keras.NET

\section{Цыганова И.А. \\ Проблемно-ситуационный анализ для моделирования организации продаж на примере пиротехнической продукции}

doi: $10.18411 / \mathrm{j}-05-2021-24$

Оренбургский государственный университет (Россия, Оренбург)

\section{Аннотация}

Увеличение ассортимента продукции, потери контроля над продажами влияют на финансовые результаты и на цепочку поставок. Именно выбор правильной политики продаж может существенно исправит ситуацию. Целью настоящего исследования является проведение проблемно-ситуационного анализа процесса организации продаж пиротехнической продукции. На основе полученных результатов провести моделирование и разработку готового к использованию программного средства, которое можно адаптировать в режиме реального времени к индивидуальным потребностям любого предприятия.

Ключевые слова: проблемные ситуации управления, система поддержки принятия решений, поставщики.

\section{Abstract}

An increase in the range of products, loss of control over sales affect financial results and the supply chain. It is the choice of the right sales policy that can significantly improve the situation. The purpose of this study is to conduct a problem-situational analysis of the process of organizing sales of pyrotechnic products. Based on the results obtained, simulate 
and develop a ready-to-use software tool that can be adapted in real time to the individual needs of any enterprise.

Keywords: problem management situations, decision support system, suppliers.

Цифровизация продуктов и процессов проникает во многие области отрасли с целью повышения качества и снижения затрат. В частности, цифровые модели позволяют виртуальному моделированию прогнозировать характеристики продуктов и процессов, а также генерировать цифровое содержимое для улучшения общего рабочего процесса. Цифровая трансформация меняет привычки и процедуры на современных предприятиях. Так процесс продаж выступает многоэтапным процессом, включающим в себя решение вопросов закупки партий товаров для обеспечения товарооборота и запасов, вопросы, связанные с хранением и условиями для этого, сама продажа товара. Учитывая механизмы оптимального подбора поставщика, проведенный анализ условий доставки и хранения товаров предприятие может снизить возможные издержки и сохранить средства внутри организации.

Методами исследования выступают ситуационный и системный анализ. Рассмотреть проблему, выяснить причины, приведшие к изменениям во внутренней и внешней средах предприятия, планировать поиск решения позволяет анализ ситуационных факторов. В клиентоориентированной компании учитывают желания клиента, ставя его во главу Таким образом, в деятельности OОO "NNN" продажа пиротехнической продукции занимает одну из лидирующих позиций в рамках выработки стратегии развития. При этом фактическое состояние процессов управления существенно отличается от планируемого. Для моделирования подобных проблемных ситуаций управления (ПСУ) применяют ситуационный подход, который позволяет рассматривать объект управления как совокупность упорядоченных согласно цели ПСУ.

В результате последовательной декомпозиции по уровням детализации построена структурная схема базовых ПСУ по организации продаж пиротехнической продукции, представленная на рисунке 1.

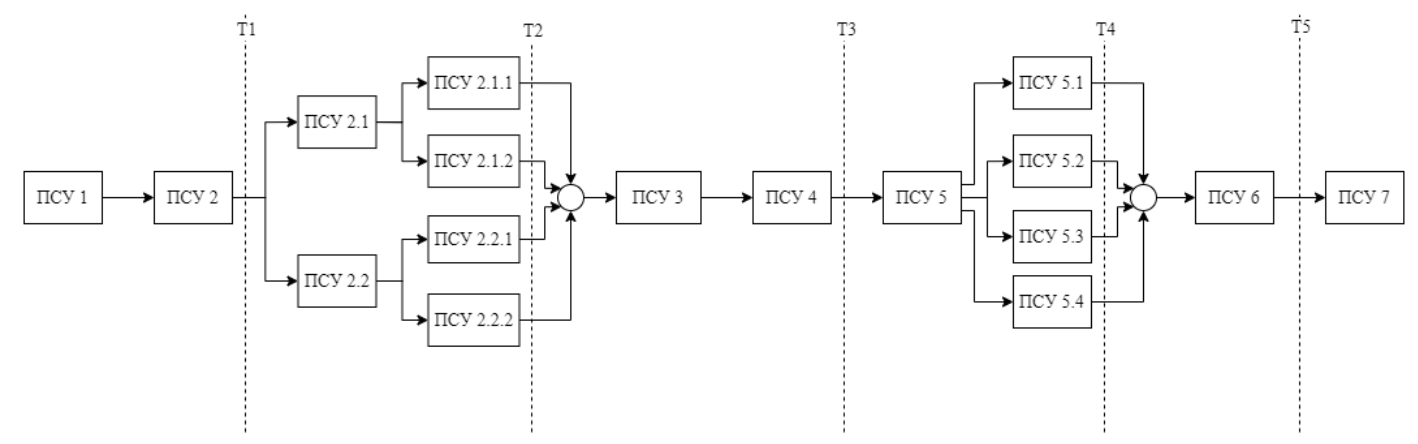

Рисунок 1 - Схема проблемных ситуаций управления

Обозначения на рисунке:

ПСУ 1 - Организация продаж

ПСУ 2 - Подбор поставщика

ПСУ 2.1 - Анализ закупки

ПСУ 2.1.1 - Оценка номенклатур

ПСУ 2.1.2 - Расчет и оценка стоимости закупки

ПСУ 2.2 - Оценка поставщиков

ПСУ 2.2.1 - Оценка критериев поставщиков

ПСУ 2.2.2 - Оценка требований поставщиков

ПСУ 3 - Формирование закупки

ПСУ 4 - Формирование остатков 
ПСУ 5 - Подбор товара

ПСУ 5.1 - Оценка калибра

ПСУ 5.2 - Оценка количества залпов

ПСУ 5.3 - Оценка числа эффектов

ПСУ 5.4 - Оценка цены

ПСУ 6 - Проверка срока годности

ПСУ 7 - План продаж

Рассмотрим проблемно-ситуационный анализ процесса организации полного цикла продажи, так как на каждом шаге возникают проблемы, решение которых влияет на дальнейшую работу и решение, принятое системой.

Организация продаж (ПСУ 1) Основной целью системы является поддержка принятия решения по организации продаж пиротехнической продукции.

Подбор поставщика ПСУ 2 влияет на этап закупки, выбирается поставщик с наиболее выгодными условиями и требованиями. ПСУ подбор поставщика разбивается на две более мелкие, но не менее важные ПСУ: ПСУ 2.1 - Анализ закупки и ПСУ 2.2 Оценка поставщиков.

Анализ закупки подразумевает анализ списка товаров, поступивший из плана закупок. Анализ закупки включает ПСУ 2.1.1 - Оценку номенклатур - наименований товаров и ПСУ 2.1.2 - Расчет и оценка стоимости закупки, стоимость закупки оценивается в соответствии с требованиями поставщиков.

Оценка поставщиков включает ПСУ 2.2.1 - подбор поставщика по выбранным критериям: срок сотрудничества, процент брака, расстояние доставки, стоимость 1 кг веса за 1 км и ПСУ 2.2.2 - условия поставщика: минимальный вес заказа.

Данные всех вышеперечисленных ПСУ формируют ПСУ 3 - формируют закупку, в которой уже отражен список товаров, вес закупки, ее стоимость и оптимально подобранный поставщик.

ПСУ 4 - Формирование остатков включает этап оприходования товаров на склад и формирование остатков товаров, также на этом этапе каждому товару присваивается свой срок хранения, который будет в дальнейшем учитываться при продаже товара.

Процедура подбора товара (ПСУ 5) осуществляется на основании оценок его характеристик.

Проверка срока реализации (ПСУ 6) рассматриваемого товара проодится следующим образом: дата истечения срока годности продаваемого товара не должна быть позже текущей даты.

Формирование плана продаж (ПСУ 7) осуществляется на основании выбранного товара по определенным критериям и проверки его даты реализации.

При проектировании программного средства, используя разработанную структурную схему, представим макет системы поддержки принятия решений (СППР). Макет СППР приведен на рисунке 2.

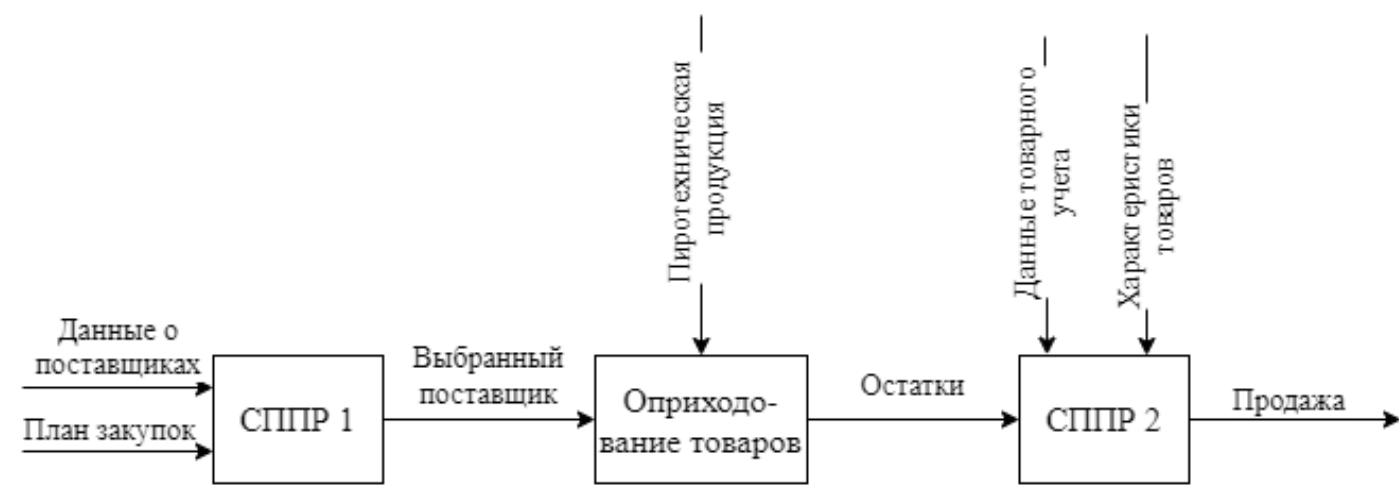

Рисунок 2 - Макет СППР 
Исходной информацией для работы информационной системы являются сведения о поставщиках, номенклатура и характеристики пиротехнической продукции и её план, данные по товарному учету.

На выходе работы системы формируются данные по вариантам оптимально подобранного поставщика и на основании этого создаваемая сопровождающая документации.

Информационную систему поддержки принятия решений можно разделить на две СППР. СППР1 представляет собой процедуру, осуществляющую выбор поставщика, собирая для этого информацию о планируемой закупке, вариантах поставщиков, используемых критериях и требованиях. Выбор поставщика реализуются методом экспертных оценок по приоритетным критериям: время сотрудничества, удельный вес брака на 100 единиц товара, расстояние доставки, стоимость доставки. Алгоритм работы на основе разработанной системы правил включает проверку соответствия основных требований закупки требованиям поставщика. Например, работа правила следующая - ЕСЛИ ( сумма закупки больше или равна требуемой поставщиком минимальной стоимость закупки) И (вес закупки меньше или равен требуемому весу закупки), ТО поставщик подходит. Отработав подобного рода правила, программное средство сформирует приемлемые варианты поставщиков продукции.

Менеджер на основе отобранного списка выбирает конкретного поставщика и проводит в системе закупку. По факту поступления товара проводится его оприходование на склад с созданием документа «Приход на склад». На данном этапе актуализируется информация об общих остатках склада, учитывая остатки на начало и приход товара.

В качестве СППР2 разработан модуль помощника продаж, необходимый непосредственно для этапа продаж. С помощью него формируется продажа, учитывая предпочтения покупателя. Товары определенных ассортиментных групп пиротехнической продукции отличаются по основным характеристикам (количество залпов, калибр, количество эффектов). При оформлении заказа покупателя менеджер, используя систему, достаточно легко формирует предложение, полностью подходящего под его запрос.

Выбранный инструмент проектирования «1С.Предприятие 8.3» и методы позволили создать информационную систему поддержки принятия решений по организации продаж пиротехнической продукции с помощью программного средства, позволяющую решить проблемы товарооборота. Рассмотрим информационную систему на примере работы пиротехнического предприятия ОOО «NNN» с цель формирования плана закупок и повышения клиентоориентированности. На рисунке 3 представлена экранная форма Помощника продаж.

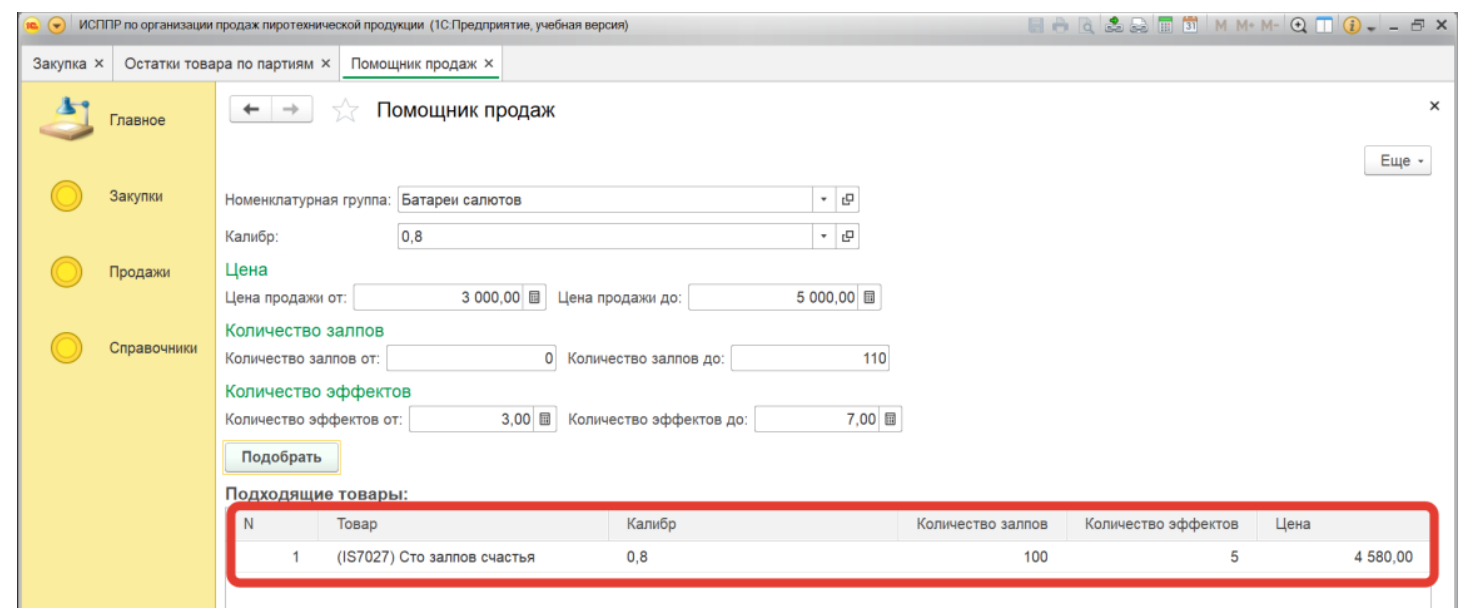

Рисунок 3 - Результат работье «Помощчника продаж» 
Таким образом, программное средство по поддержки принятия решений по организации продаж пиротехнической продукции обеспечивает менеджера мощным аппаратом для выбора наиболее подходящего поставщика в конкретный момент времени и удовлетворения нужд потребителя наиболее обоюдовыгодным образом.

Разработанное инструментальное средство является универсальным и может быть настроено на организацию продаж предприятий другого профиля.

$$
* * *
$$

1. Королева, В. Л. Методы выбора поставщиков / В. Л. Королева. - Текст : непосредственный // Экономика, управление, финансы : материалы V Междунар. науч. конф. (г. Краснодар, август 2015 г.). — Краснодар : Новация, 2015. — C. 83-84. — URL: https://moluch.ru/conf/econ/archive/204/8585

2. Загоруйко, Н. Г. Прикладные методы анализа данных и знаний. - Новосибирск: ИМ СО РАН, 2014. -245 c. - ISBN 5-86134-060-9.

Шестакова А.С., Леонова Е.А.

Структурно-функциональная модель процесса написания научной статьи

Южно-Уральский государственный гуманитарно-педагогический университет (Россия, Челябинск) doi: $10.18411 / 1 j-05-2021-25$

Научный руководитель Леонова Е.А.

\section{Аннотация}

В статье рассмотрена модель подготовки научно-практической (эмпирической) статьи, в которой изложены результаты педагогического исследования.

Ключевые слова: научная статья, функциональные методики, проектирование, информационная система.

\section{Abstract}

The article considers the model of preparation of a scientific-practical (empirical) article, which presents the results of pedagogical research.

Keywords: scientific article, functional methods, design, information system.

Практически каждый студент хотя бы раз в своей жизни писал научную статью. Для кого-то данный процесс не является столь обременительным, а кому-то приходится поломать голову прежде чем получить нужный результат. В связи с этим возникла потребность разработать модель информационной системы подготовки и написания научной статьи.

Научная статья - это логически завершенное исследование какой-либо проблемы, осуществленное посредством применения научного метода [1]. Научная статья предполагает изложение собственных выводов и промежуточных или окончательных результатов своего научного исследования, экспериментальной или аналитической деятельности. Такая статья должна содержать авторские разработки, выводы, рекомендации.

В любой публикации такого рода описывается актуальность исследования, цели и задачи изыскания, а также суть новаторства изложенных идей. Автор, публикуя свое исследование, закрепляет за собой авторское право на ту или иную идею.

Существуют разные виды научных статей:

1. Научно-теоретические - описывающие результаты исследований, выполненных на основе теоретического поиска и объяснения явлений и их закономерностей.

2. Научно-практические (эмпирические) - построенные на основе экспериментов и реального опыта. 